\title{
MONITORAMENTO DA QUALIDADE DO AR NO MUNICÍPIO DE CASCAVEL - PR POR ANALISADOR PORTÁTIL DE GASES
}

\author{
Joao Karlos Koyama \\ José Hilton Bernardino de Araújo \\ Renan Freitas Silva
}

\begin{abstract}
RESUMO
O setor automobilístico tem aumentado constantemente no Brasil, o que contribui para uma maior quantidade de veículos em transito pelas ruas. As emissões decorrentes dos meios de transportes terrestres têm impactos significativos na qualidade do ar e na saúde humana. O Presente trabalho teve como objetivo monitorar e analisar as concentrações dos poluentes atmosféricos emitidos por fontes moveis em cinco pontos distribuídos de forma estratégica ao longo do município de Cascavel, Paraná durante o período 12 de março a 2 junho de 2014. Além disso fazer a quantificação do número de veículos para fazer um banco de dados atualizado que poderá servir para melhorias no transito do município. Foi constatado que apesar de serem registradas algumas medições com concentrações superiores as estabelecidas pela Resolução Conama 03/1990, a frota de veículos que circularam durante as medições não foram fator determinante na emissão dos poluentes, porém o estado de manutenção dos veículos foi identificado como um dos fatores que interferem na qualidade do ar. As variáveis climáticas também influenciaram na quantificação e monitoramento dos poluentes.

PALAVRAS-CHAVE: Emissão atmosférica, monóxido de carbono, trânsito.
\end{abstract}

\section{AIR QUALITY MONITORING IN CASCAVEL COUNTY - PR FOR PORTABLE GAS ANAL YZER}

\begin{abstract}
The automobile sector has increased steady in Brazil, which contributes to a greater amount of vehicles in the streets. Emissions from the means of transportation have significant impacts on air quality and human health. The present study aimed to monitor and analyze the concentrations of air pollutants emitted by mobile sources in five points distributed strategically throughout Cascavel city in Paraná from March 12th to June 2nd, 2014. Besides quantification of the number of vehicles was made in order to have an updated database that can be used for traffic improvements in the city. It was found that although some measurements recorded higher concentrations than the ones established by CONAMA Resolution 03/1990, the vehicles which passed during the measurements were not a determining factor in the emission of pollutants. However, their bad maintenance was identified as one of the factors that affects air quality. The climate changing also influenced in the quantification and monitoring of pollutants.
\end{abstract}





\section{Revista Nacional de}

Gerenciamento de Cidades

atmosfera oriundas dos escapamentos dos veículos, das chaminés das fabricas e das queimadas, que lançam constantemente no ar grandes quantidades de substâncias prejudiciais à saúde humana e ao meio ambiente. Estas emissões geram problemas ambientais como a degradação de florestas e da camada de ozônio, agravamento do efeito estufa e a ocorrência de chuvas ácidas. Atualmente, a poluição do ar é um dos maiores problemas que afeta a saúde pública, causando problemas aos seres humanos, animais e plantas (OGA et al., 2008).

Segundo Freitas (2006), devido ao crescimento do setor automobilístico, a quantidade de veículos transitando pelas cidades contribuem bastante para a poluição do ar, devido a queima de combustíveis em seus motores. A poluição atmosférica pode ser causada por duas fontes, chamadas de fixas ou móveis. Os veículos (fontes móveis) são um dos principais responsáveis por estas emissões devido ao grande número que circulam nos centros urbanos. Vale ressaltar que, embora existam fontes fixas e móveis de emissores de poluentes, os gases tendem a se dispersar no ambiente, podendo vir a poluir áreas próximas ou mais distantes da fonte.

O Conselho Nacional do Meio Ambiente (CONAMA) $N^{\circ} 3$, de 28 de junho de 1990, na esfera federal, dispõe sobre os padrões de qualidade do ar que se ultrapassadas as concentrações máximas podem afetar a saúde e o bem-estar da população, bem como ocasionar danos à flora e à fauna, aos materiais como obras públicas. No Brasil foram adotadas medidas como o Programa Nacional de Controle de Poluição por Veículos Automotores (PROCONVE) com a finalidade de reduzir os níveis de poluição veicular.

Desta forma, este trabalho visa acompanhar e monitorar as emissões de poluentes atmosféricos em pontos estratégicos do município de Cascavel, estado do Paraná, e comparar os dados com a legislação vigente relacionada com padrões de qualidade do ar. 



\section{Revista Nacional de}

fabricado por BW Technologies, o qual apresenta a concentração momentânea dos poluentes $\mathrm{H}_{2} \mathrm{~S}$, e $\mathrm{CO}$ em concentração em partes por milhão (ppm), e $\mathrm{O}_{2}$ e gases combustíveis, em porcentagem (\%). As aferições foram efetuadas nos horários onde há maior concentração de veículos, entre 07h00 e 08h00, 12h00 e 13h00 e 17h00 e 18h00, sempre de segunda à sexta, respeitando o horário nacional de Brasília-DF. Estas medições foram realizadas no período desde o mês de março de 2014 até o mês de junho de 2014.

Nos locais de monitoramento além do medidor portátil, foi utilizado prancheta, ficha de campo e caneta para a anotação. Como a cidade de Cascavel é uma das cidades mais populosas do Paraná e com intenso movimento de veículos, para anotar com melhor precisão a quantidade de veículos foi necessário o auxílio de outra pessoa. Os veículos foram separados em quatro categorias: pesados que compreenderão os ônibus e caminhões; os médios que compreenderão as camionetes e utilitários; os leves que compreenderão os veículos de passeio; e também as motocicletas; que transitaram durante o período das amostragens para relacionar com a quantidade emitida de poluentes atmosféricos. Para análise das situações favoráveis ou inconformidades foi utilizado como base o padrão de qualidade do ar referente à emissão de Monóxido de Carbono (CO), disposto na Resolução CONAMA ํㅜ 3, de 28 de junho de 1990.

\section{RESULTADOS E DISCUSSÃO}

Os veículos contabilizados durante as 15 amostragens, registraram um total de 62.542 veículos, conforme a Tabela 1. Desta forma para veículos leves compreendem-se automóveis de passeio, veículos médios as camionetes e utilitários, veículos pesados os ônibus e caminhões e as motocicletas. 


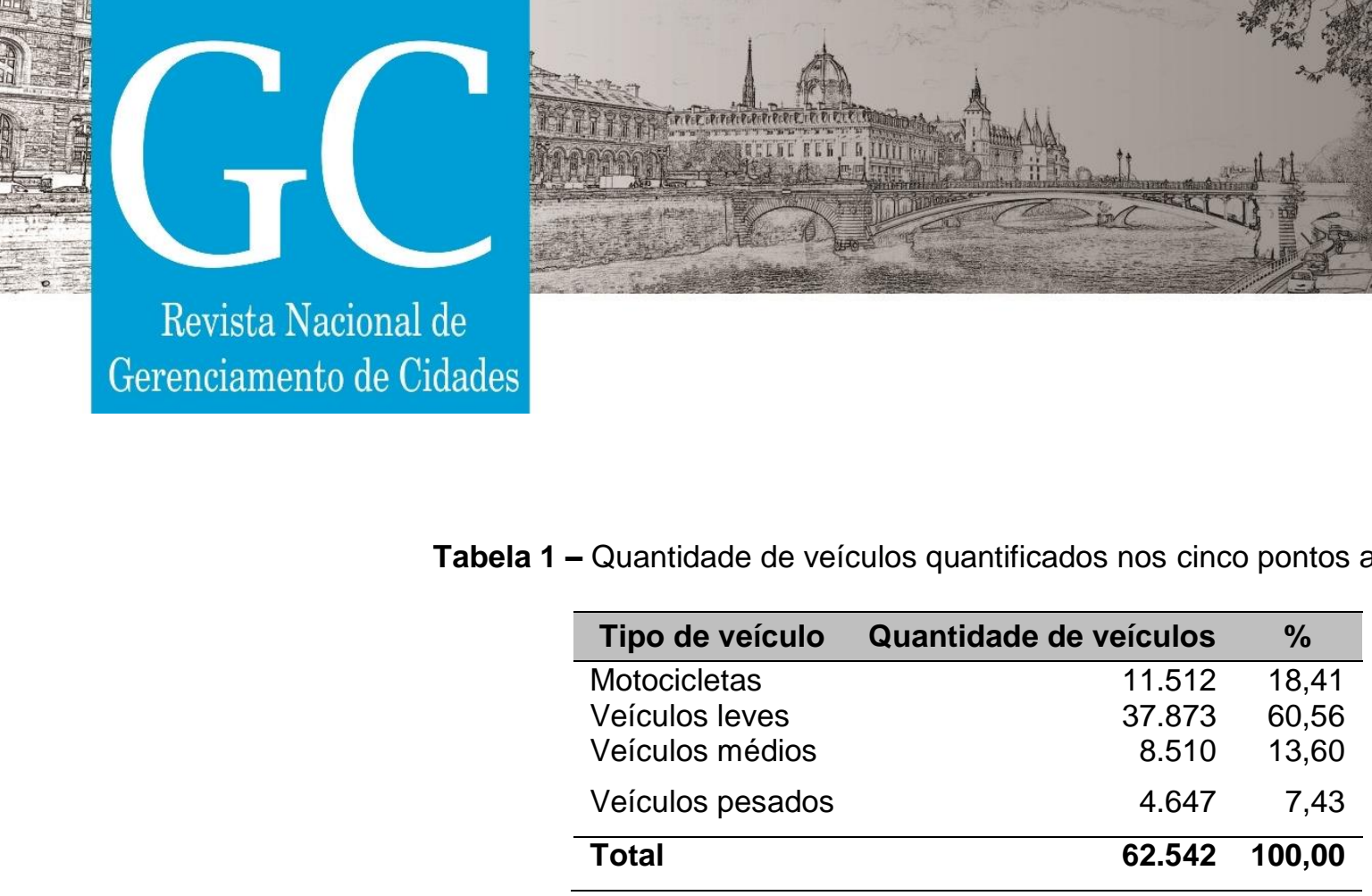

\section{Revista Nacional de}

Gerenciamento de Cidades

Tabela 1 - Quantidade de veículos quantificados nos cinco pontos amostrais.

\begin{tabular}{lrr}
\hline Tipo de veículo & Quantidade de veículos & $\%$ \\
\hline Motocicletas & 11.512 & 18,41 \\
Veículos leves & 37.873 & 60,56 \\
Veículos médios & 8.510 & 13,60 \\
Veículos pesados & 4.647 & 7,43 \\
\hline Total & $\mathbf{6 2 . 5 4 2}$ & $\mathbf{1 0 0 , 0 0}$ \\
\hline
\end{tabular}

Conforme as estatísticas fornecidas pelo DETRAN/PR, no munícipio de Cascavel, até o mês de março do presente ano, foram registrados 193.147 veículos, dispostos conforme a Tabela 2 .

Tabela 2 - Quantidade de veículos registrados pelo DETRAN/PR até o mês de março de 2014.

\begin{tabular}{lrr}
\hline Tipo de veículo & Quantidade de veículos & $\%$ \\
\hline Motocicletas & 37.412 & 19,37 \\
Veículos leves & 111.726 & 57,84 \\
Veículos médios & 23.328 & 12,09 \\
Veículos pesados & 20.681 & 10,70 \\
\hline Total & $\mathbf{1 9 3 . 1 4 7}$ & $\mathbf{1 0 0 , 0 0}$ \\
\hline \multicolumn{2}{c}{ Fonte: DETRAN - PR (2014). (adaptado). }
\end{tabular}

Ao se comparar os valores encontrados durante a realização do trabalho com os valores fornecidos pelo DETRAN/PR, pode-se observar que durante as amostragens foram contabilizados aproximadamente $32 \%$ dos veículos registrados pelo DETRAN/PR, essa diferença nos números encontrados pode acontecer devido á população utilizar trajetos diferentes onde foram instalados os postos de observação e também a existência de veículos cadastrados que não estão em uso.

As temperaturas nos dois primeiros dias em geral ficaram próximas dos $27^{\circ} \mathrm{C}$, com tempo seco e ensolarado, Já no dia 30/05/2014 registrou-se mínima de $6^{\circ} \mathrm{C}$ no período entre $7 \mathrm{~h} 00$ e $8 \mathrm{~h} 00$, embora a ocorrência desse fator não proporcionar significativas mudanças no numero de veículos contabilizados. $\mathrm{Na}$ 


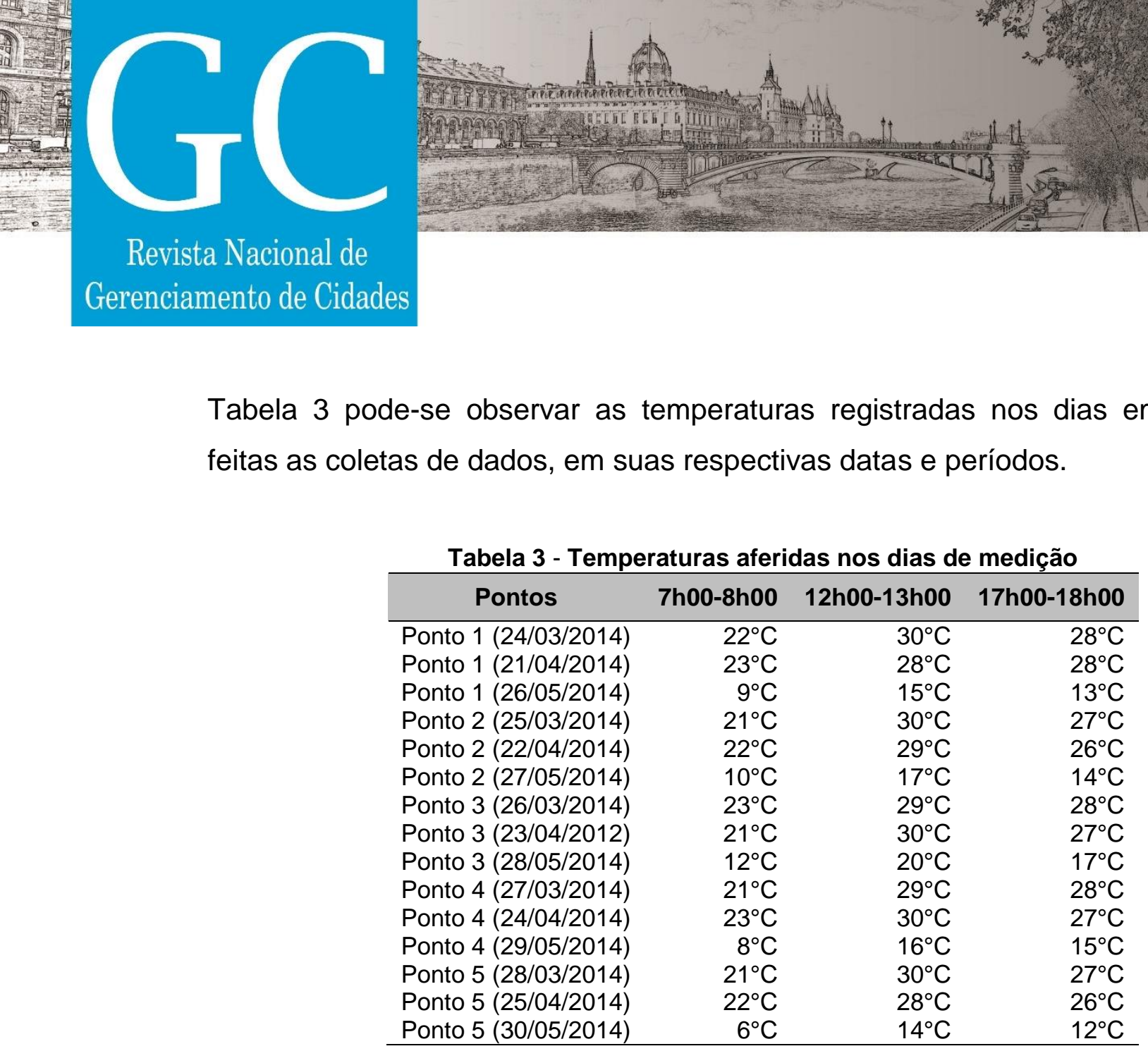

Tabela 3 pode-se observar as temperaturas registradas nos dias em que foram

A concentração de gás sulfídrico $\left(\mathrm{H}_{2} \mathrm{~S}\right)$ foi nula durante todas as amostragens. Segundo Andrade et al., (2009), a justificativa dessa ocorrência se da pela reação do $\mathrm{H}_{2} \mathrm{~S}$ com o oxigênio atmosférico, assim formando o dióxido de enxofre $\left(\mathrm{SO}_{2}\right)$, o qual não é detectado pelo equipamento utilizado. $\mathrm{O}$ oxigênio permaneceu com valor inalterado de $20,9 \%$ em todas as coletas de dados. De acordo com a Resolução CONAMA 03/1990, as detecções que apontarem concentrações maiores ou igual a 35 partes por milhão (ppm), estariam impróprias a saúde e bem estar da saúde humana.

As Figuras 2, 3 e 4 apresentam as concentrações obtidas nas amostragens no Ponto 1. As Figuras 5, 6 e 7 apresentam as concentrações obtidas nas amostragens no Ponto 2. As Figuras 8, 9 e 10 apresentam as concentrações das amostragens no ponto 3. As Figuras 11, 12 e 13 apresentam as concentrações das amostragens no Ponto 4. As Figuras 14, 15 e 16 demonstram os valores nos determinados horários de coleta no Ponto 5. 


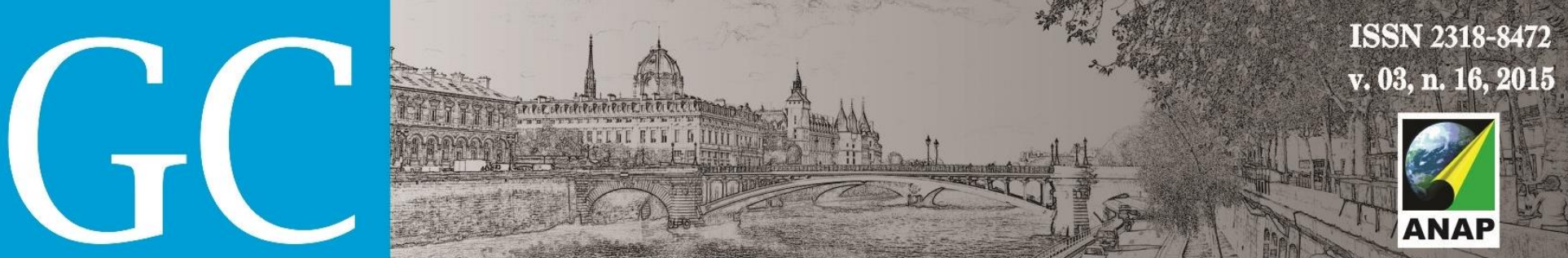

Revista Nacional de

Gerenciamento de Cidades

Figura 1 - Concentração de CO no dia 24/03/2014 e nos horários A 7h00min as $8 \mathrm{~h} 00 \mathrm{~min}, \mathrm{~B} 12 \mathrm{~h} 00 \mathrm{~min}$ as $13 \mathrm{~h} 00 \mathrm{~min}, \mathrm{C} 17 \mathrm{~h} 00 \mathrm{~min}$ as $18 \mathrm{~h} 00 \mathrm{~min}$ no Ponto 1.

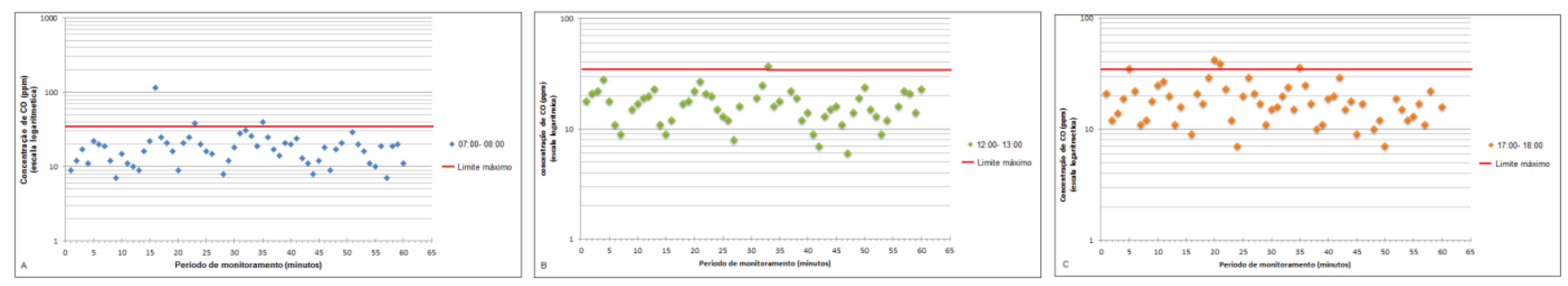

Figura 32 - Concentração de CO no dia 21/04/2014 e nos horários A 7h00min as 8h00min, B $12 \mathrm{~h} 00 \mathrm{~min}$ as $13 \mathrm{~h} 00 \mathrm{~min}, \mathrm{C} 17 \mathrm{~h} 00 \mathrm{~min}$ as $18 \mathrm{~h} 00 \mathrm{~min}$ no Ponto 1.

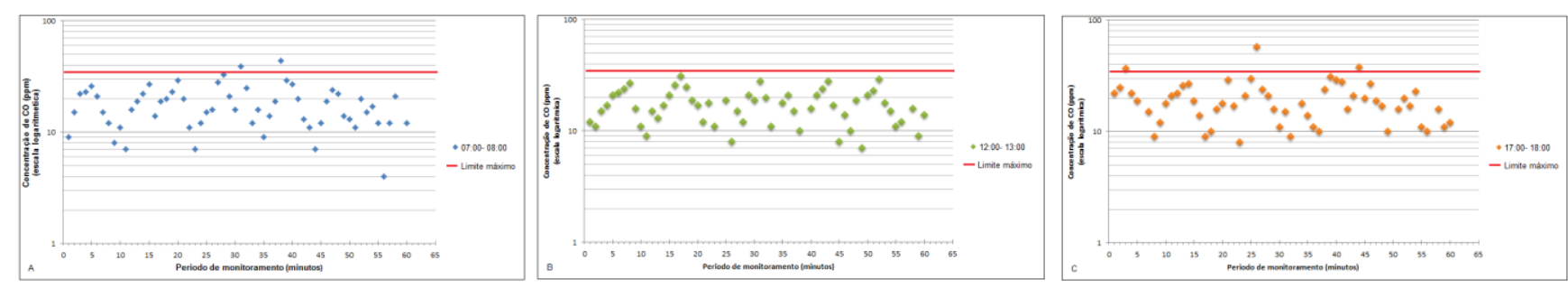

Figura 4 - Concentração de CO no dia 26/05/2014 e nos horários A 7h00min as 8h00min, B $12 \mathrm{~h} 00 \mathrm{~min}$ as $13 \mathrm{~h} 00 \mathrm{~min}, \mathrm{C} 17 \mathrm{~h} 00 \mathrm{~min}$ as $18 \mathrm{~h} 00 \mathrm{~min}$ no Ponto 1.
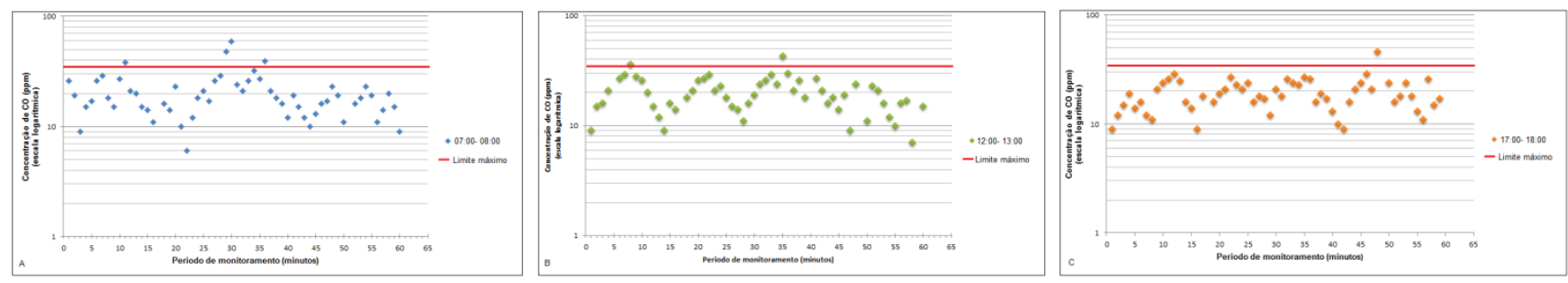

Figura 53 - Concentração de CO no dia 25/03/2014 e nos horários A 7h00min as 8h00min, B $12 \mathrm{~h} 00 \mathrm{~min}$ as $13 \mathrm{~h} 00 \mathrm{~min}, \mathrm{C} 17 \mathrm{~h} 00 \mathrm{~min}$ as $18 \mathrm{~h} 00 \mathrm{~min}$ no Ponto 2.

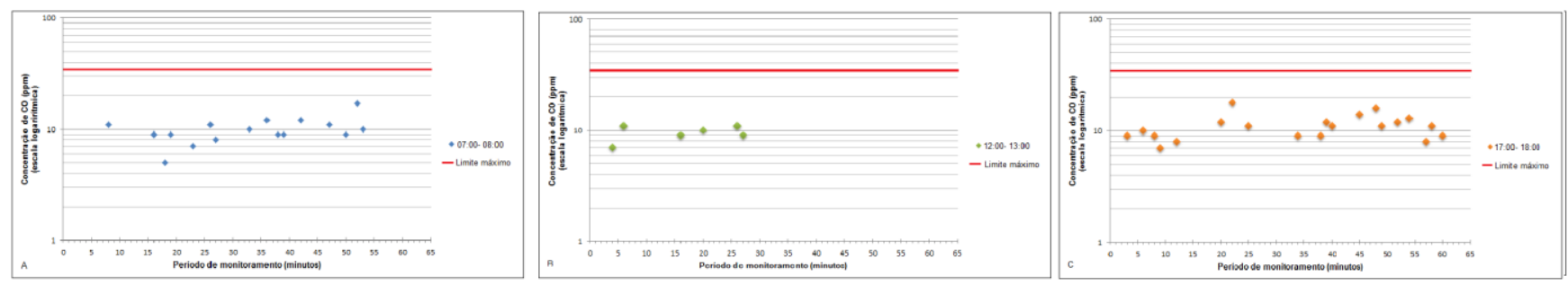




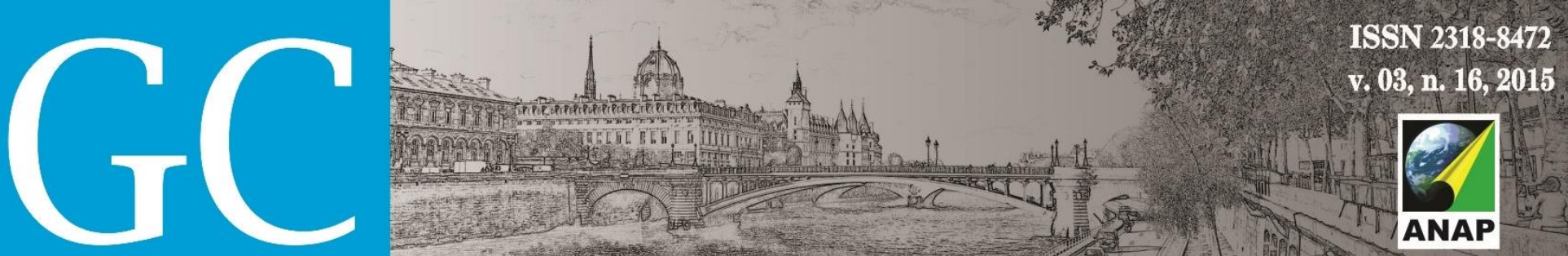

Revista Nacional de

Gerenciamento de Cidades

Figura 107 - Concentração de CO no dia 28/05/2014 e nos horários A 7h00min as 8h00min, B $12 \mathrm{~h} 00 \mathrm{~min}$ as $13 \mathrm{~h} 00 \mathrm{~min}, \mathrm{C} 17 \mathrm{~h} 00 \mathrm{~min}$ as $18 \mathrm{~h} 00 \mathrm{~min}$ no Ponto 3.

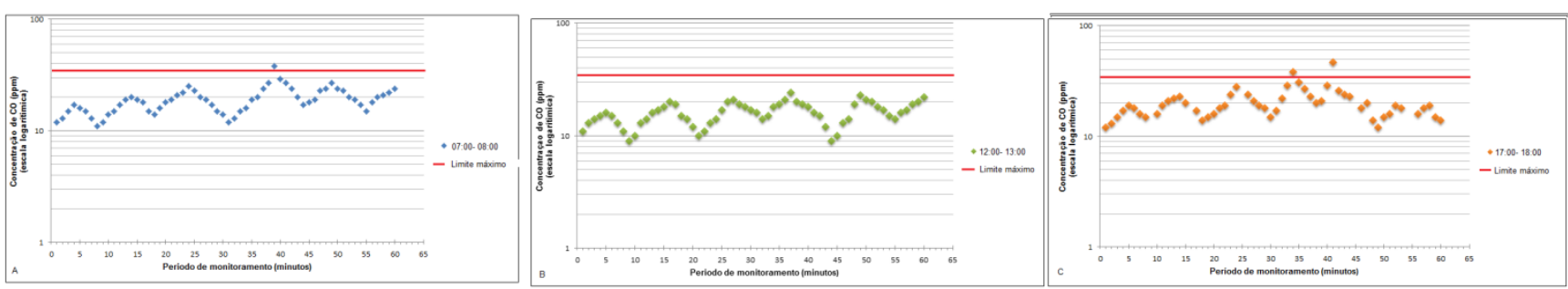

Figura 8 - Concentração de CO no dia 27/03/2014 e nos horários A 7h00min as 8h00min, B $12 \mathrm{~h} 00 \mathrm{~min}$ as $13 \mathrm{~h} 00 \mathrm{~min}, \mathrm{C} 17 \mathrm{~h} 00 \mathrm{~min}$ as $18 \mathrm{~h} 00 \mathrm{~min}$ no Ponto 4.

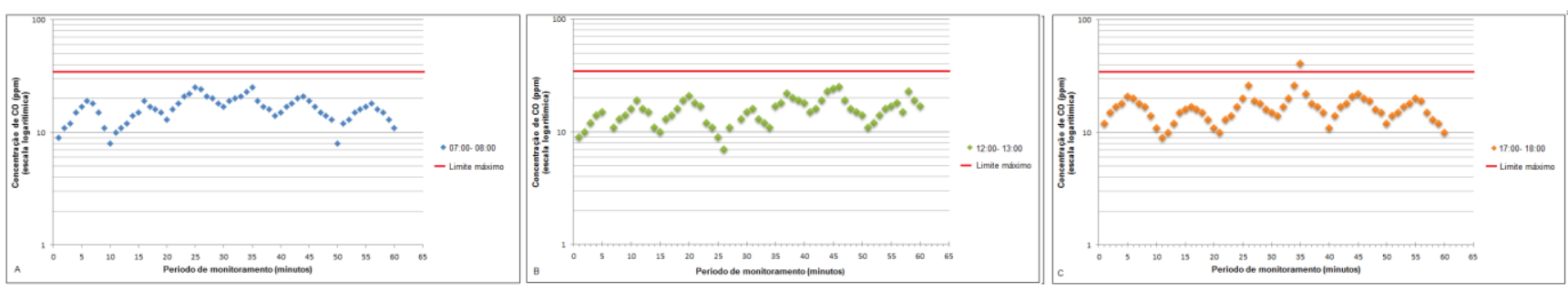

Figura 12 - Concentração de CO no dia 24/04/2014 e nos horários A 7h00min as 8h00min, B $12 \mathrm{~h} 00 \mathrm{~min}$ as $13 \mathrm{~h} 00 \mathrm{~min}, \mathrm{C} 17 \mathrm{~h} 00 \mathrm{~min}$ as $18 \mathrm{~h} 00 \mathrm{~min}$ no Ponto 4.
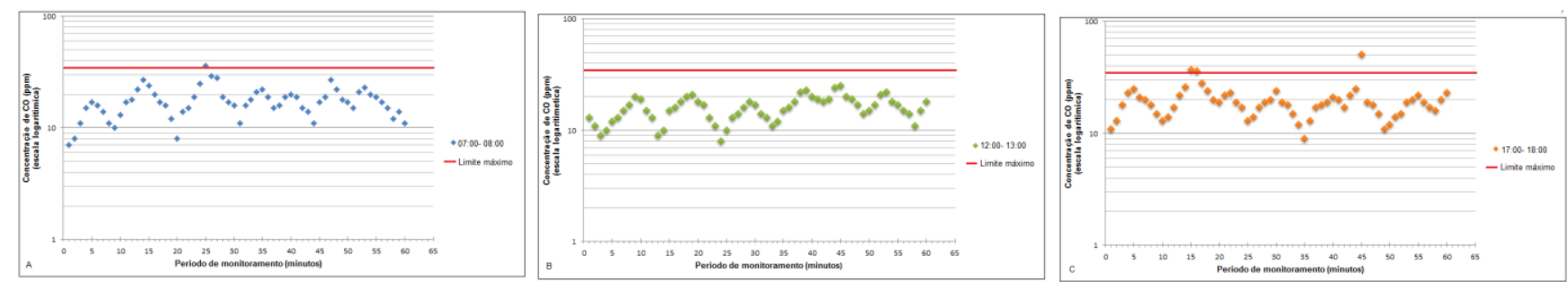

Figura 13 - Concentração de CO no dia 29/05/2014 e nos horários A 7h00min as 8h00min, B $12 \mathrm{~h} 00 \mathrm{~min}$ as $13 \mathrm{~h} 00 \mathrm{~min}, \mathrm{C} 17 \mathrm{~h} 00 \mathrm{~min}$ as $18 \mathrm{~h} 00 \mathrm{~min}$ no Ponto 4.
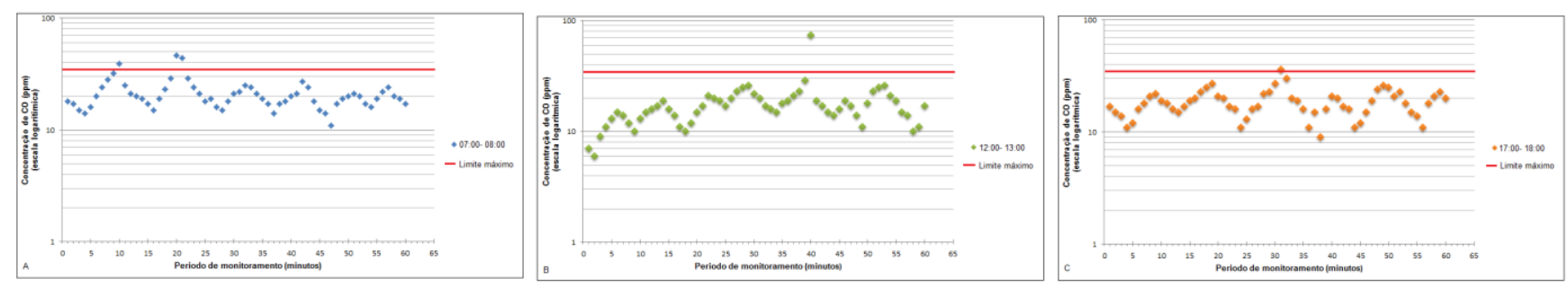


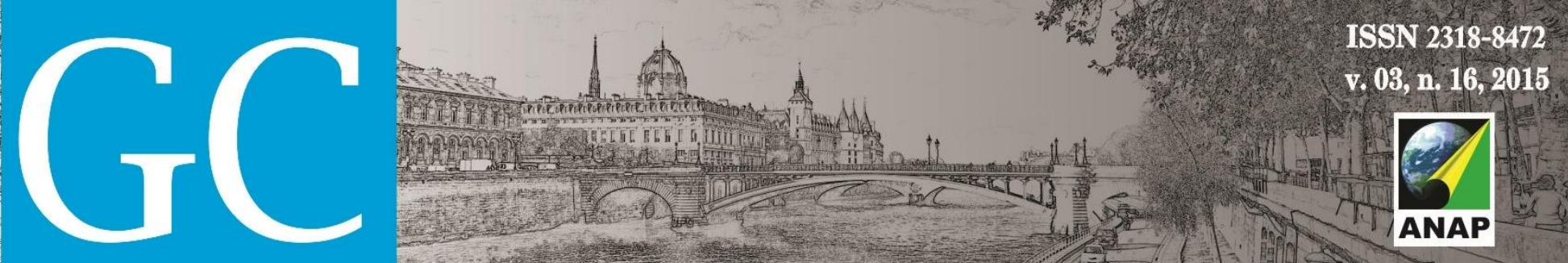

Revista Nacional de

Gerenciamento de Cidades

Figura 14 - Concentração de CO no dia 28/03/2014 e nos horários A $7 \mathrm{~h} 00 \mathrm{~min}$ as $8 \mathrm{~h} 00 \mathrm{~min}$, B $12 \mathrm{~h} 00 \mathrm{~min}$ as $13 \mathrm{~h} 00 \mathrm{~min}, \mathrm{C} 17 \mathrm{~h} 00 \mathrm{~min}$ as $18 \mathrm{~h} 00 \mathrm{~min}$ no Ponto 5.

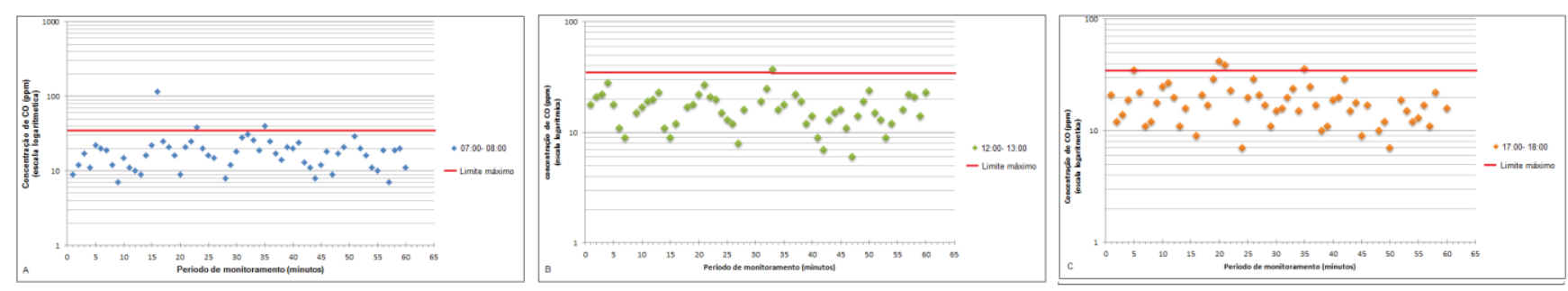

Figura 15 - Concentração de CO no dia 25/04/2014e nos horários A 7h00min as 8h00min, B $12 \mathrm{~h} 00 \mathrm{~min}$ as $13 \mathrm{~h} 00 \mathrm{~min}, \mathrm{C} 17 \mathrm{~h} 00 \mathrm{~min}$ as $18 \mathrm{~h} 00 \mathrm{~min}$ no Ponto 5.
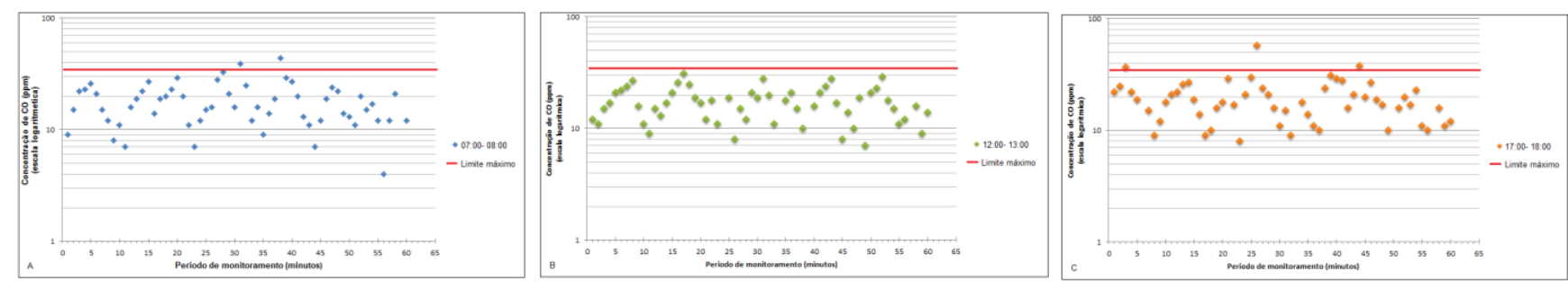

Figura 16 - Concentração de CO no dia 30/05/2014 e nos horários A $7 \mathrm{~h} 00 \mathrm{~min}$ as $8 \mathrm{~h} 00 \mathrm{~min}$, B $12 \mathrm{~h} 00 \mathrm{~min}$ as $13 \mathrm{~h} 00 \mathrm{~min}, \mathrm{C} 17 \mathrm{~h} 00 \mathrm{~min}$ as $18 \mathrm{~h} 00 \mathrm{~min}$ no Ponto 5.
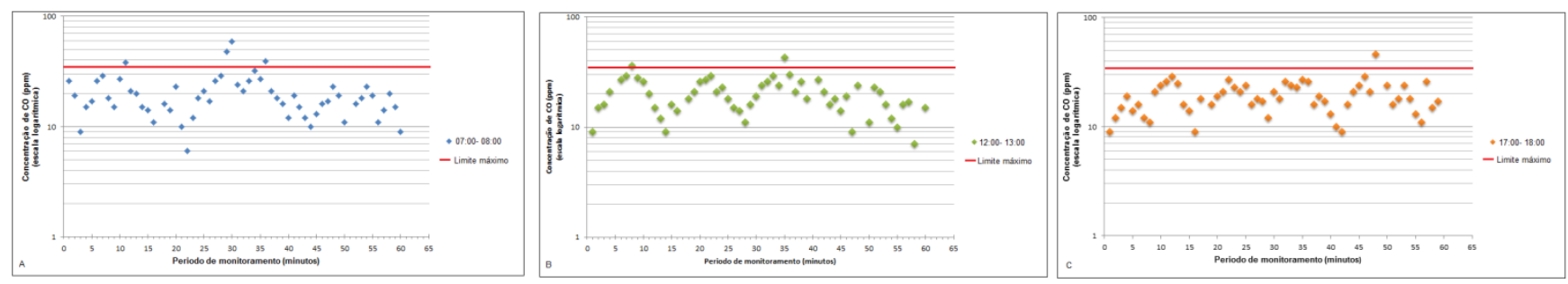

No ponto 1 foi o local onde se obteve o maior índice de picos registrados no medidor portátil de gases. Durante os horários de amostragem além do grande fluxo de veículos percebeu-se que ocorriam frequentemente congestionamentos, isso porque a presença de um semáforo trava o trafego, e com a permanência dos veículos parados no local, ocorre maior liberação de poluentes na atmosfera.

Nos pontos localizados no centro da cidade (Pontos 3 e 4), foram onde registrou-se os maiores picos de amostragem de monóxido de carbono. Em ambos 


\section{Revista Nacional de}

se tem a presença de um semáforo, e também a presença de prédios ao redor, com isso, a amplitude do local pode ter influencia na concentração de gases, fazendo com que os poluentes demorem mais para se dispersar. Vale salientar que uma possível solução seria diminuir o tempo que o semáforo fica no vermelho, diminuindo o tempo de permanência dos veículos nesse local. No ponto 5 embora o local tenha um fluxo constante de automóveis sem a interrupção de semáforo, frequentemente os veículos são obrigados a parar totalmente por conta do intenso movimento e forçar seus motores para arrancar, por conta disso também ocorreu um grande numero de detecções do aparelho.

De acordo com os gráficos em todos os dias de coleta o nível de CO foi ultrapassado várias vezes, chegando a ultrapassar 100 (ppm) no primeiro dia de coleta. O estado de manutenção dos veículos foi um fator importante no número de detecções registradas, visto que durante as medições frequentemente eram observados veículos em más condições.

Como a localização do Ponto 5 é semelhante ao ponto 1, ambos estão em um trevo que dá acesso a outras cidades, as características do tráfego de veículos também são semelhantes.

\section{CONCLUSÃO}

A partir dos resultados obtidos verificou-se que não houve uma relação entre as concentrações de monóxido de carbono com a quantidade de automóveis que trafegaram nos pontos de amostragem. Apesar de não ter sido registrado $o$ ano de fabricação dos veículos contabilizados, notou-se que o grau de conservação destes veículos influenciava na emissão de poluentes e também o tempo de permanecia destes veículos parados no local.

Em termos de saúde publica há de ressaltar os problemas provenientes dos gases poluentes, que durante os períodos mais secos do ano, acabam agravando ainda mais a saúde das pessoas susceptíveis a doenças respiratórias e pulmonares. Após esse estudo sugere-se que seja implantado um programa municipal de 


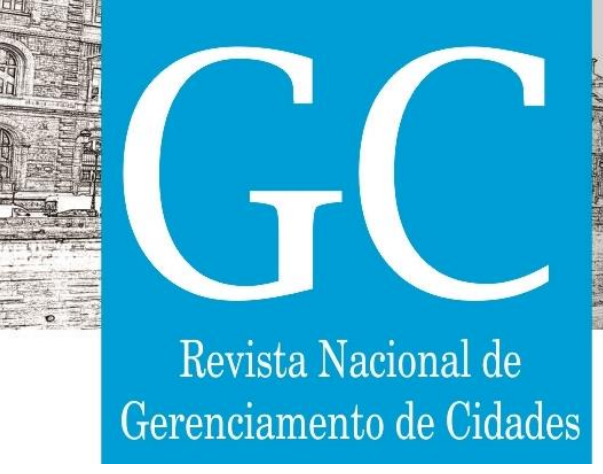

PARANÁ (Estado). Secretaria do Estado da Segurança Pública - Departamento de Transito do Paraná - DETRAN PR. Frota de veículos cadastrados no Estado do Paraná - Posição em março 2014. Paraná. 2014. 08p. Disponível em:

$<$ http://www.detran.pr.gov.br/arquivos/File/estatisticasdetransito/frotadeveiculoscadastradospr/2014/fr ota marco 2014.pdf>. Acesso em 25 abril 2014.

PREFEITURA MUNICIPAL DE CASCAVEL. Disponível: <http://www.cascavel.pr.gov.br/> Acesso em 21 dezembro 2013. 